\author{
Bartosz PRZYBYŁA ${ }^{1}$ \\ Zbigniew ZAPAŁOWICZ ${ }^{2}$
}

\title{
PRZEGLACD METOD USZCZELNIANIA WIRNIKÓW TURBIN LOTNICZYCH
}

\begin{abstract}
W artykule przedstawiono najczęściej stosowane w praktyce sposoby przeciwdziałania przeciekom strumieni powietrza lub spalin pomiędzy wirnikiem a korpusem lotniczej turbiny gazowej, materiały stosowane do budowy uszczelnień oraz wady i zalety poszczególnych rozwiazań konstrukcyjnych. Szczegółowo opisano następujące rozwiązania konstrukcyjne: uszczelnienie przez wykonanie wgłębienia w materiale końcówki łopatki wirnikowej, uszczelnienie labiryntowe, wykorzystanie do uszczelniania materiałów odpornych na ścieranie (np. węglikowe płytki zabezpieczające) oraz materiałów tworzących tzw. ,plaster miodu”.
\end{abstract}

Słowa kluczowe: silniki lotnicze, turbiny gazowe, uszczelnienia turbin

\section{Wstęp}

Silniki turbinowe są stosowane na szeroką skalę do napędów statków powietrznych, począwszy od śmigłowców, przez samoloty myśliwskie, do największych samolotów z klasycznym napędem odrzutowym bądź turbośmigłowym. Ich największą zaletą, w porównaniu z silnikami tłokowymi, jest przede wszystkim duża moc bądź duży ciąg osiągany przy stosunkowo małych gabarytach (duży współczynnik koncentracji mocy). Ogromną zaletą obecnie produkowanych i używanych silników turbinowych, w porównaniu z konstrukcjami sprzed kilkudziesięciu lat, jest również ich większa trwałość, sięgająca niekiedy 3000-6000 godzin pracy. Jednak takie napędy nie są pozbawione wad, z których największą jest stosunkowo duże zużycie paliwa, innymi są zaś: duża podatność na uszkodzenia elementów konstrukcyjnych przez ciała obce zassane przez silnik, konieczność częstego serwisowania turbin przez personel naziemny, zapewnienie dużej precyzji wykonania poszczególnych elementów konstrukcyjnych turbiny, co wpływa bezpośrednio na koszt zastosowanych materiałów i koszty produkcji.

\footnotetext{
${ }^{1}$ Autor do korespondencji/corresponding author: Bartosz Przybyła, Zachodniopomorski Uniwersytet Technologiczny w Szczecinie, al. Piastów 19, 70-310 Szczecin, tel.: (91) 4494272, e-mail: bartosz.przybyla@zut.edu.pl.

2 Zbigniew Zapałowicz, Zachodniopomorski Uniwersytet Technologiczny w Szczecinie, e-mail: zbigniew.zapalowicz@ zut.edu.pl.
} 
Uszczelnienia stosuje się między: łopatkami wirnika a kadłubem, tłokiem odciążającym a kadłubem, wałem a kadłubem oraz wałem a tarczą kierowniczą. Uszczelnieniem turbin gazowych zajmuje się wiele ośrodków badawczych oraz centrów wdrożeniowych największych producentów silników turbinowych, takich jak: Pratt\&Whitney, Rolls-Royce, General Electric, Turbomeca i in. Konieczność obniżenia kosztów utrzymania napędów powoduje, że stale poszukuje się nowych, bardziej efektywnych rozwiązań konstrukcyjnych. Często są to bardzo skomplikowane konstrukcje, takie jak: uszczelnienie wirnika przez nadmuch powietrza w szczelinę międzyłopatkową, czy też stosowanie silników typu „propfan”. W tym ostatnim rozwiązaniu konstrukcyjnym poza obracającym się wirnikiem turbiny, wiruje również kierownica, napędzając przeciwbieżny wirnik. Szacuje się, że spośród wszystkich czynników, które mają największy wpływ na pogorszenie parametrów pracy turbin, nieszczelności stanowią ponad 40\% ogółu strat [7].

Celem niniejszej pracy jest analiza obecnie stosowanych metod uszczelnienia wirników turbin gazowych.

\section{Określenie wysokości szczeliny uszczelniającej}

W silnikach turbinowych elementem, który bezpośrednio przetwarza energię kinetyczną spalin na energię mechaniczną, jest wirnik turbiny. Wirnik jest zbudowany z piasty i tarczy, na której w zależności od konstrukcji zamontowano od kilkunastu do nawet kilkuset łopatek. Pomiędzy końcówkami łopatek a korpusem turbiny musi istnieć szczelina konstrukcyjna, zabezpieczająca silnik przed jego uszkodzeniem na skutek ewentualnego kontaktu tych elementów. Wysokość tej szczeliny nie może być zbyt mała, bo oczywiście nie zabezpieczy ona łopatek wirnika przed zniszczeniem, ale nie może być też zbyt duża, ponieważ wtedy straty nieszczelności będą zbyt duże. Na wielkość szczeliny mają wpływ następujące czynniki:

- grubość warstwy filmu olejowego w łożyskach wału silnika, która zależy przede wszystkim od poprawności działania układu olejowego,

- stan łożysk wału,

- drgania silnika podczas jego pracy,

- wychylenie silnika wynikające z wykonywanych przez samolot manewrów,

- rozszerzalność cieplna łopatek przy temperaturze spalin osiągającej wartość nawet $1600 \mathrm{~K}$,

- zjawisko pełzania materiału, z którego wykonana jest łopatka,

- okres użytkowania silnika,

- podatność na rozciąganie łopatki, wynikająca z działania sił odśrodkowych przy prędkościach obrotowych wirnika osiągających wartość nawet $60000 \mathrm{obr} . / \mathrm{min}$,

- precyzja wykonania i montażu zespołów turbiny [4]. 
Wysokość szczeliny można wyznaczyć ze wzoru:

$$
C_{t}=A \cdot \frac{D_{z}}{1000}+0,25
$$

gdzie: $D_{z}$ - średnica zewnętrzna wirnika turbiny,

$A$ - współczynnik.

Wartość współczynnika $A$ wynosi odpowiednio: $A=0,6$ dla sprężarek osiowych, $A=0,85$ dla turbin wykonanych ze stali ferrytycznych, tzw. nierdzewnych, oraz $A=1,3$ dla stali austenitycznych, tzw. kwasoodpornych. Słuszność wzoru (1) można sprawdzić np. dla silnika P\&W 206 B2+. Instrukcja tego silnika podaje, że wartość wysokości szczeliny $C_{t}$ powinna się zawierać w przedziale 0,43-0,48 $\mathrm{mm}$ [2]. Elementy silnika są wykonane ze stali austenitycznej, a średnica zewnętrzna wirnika $D_{z}=170 \mathrm{~mm}$. Wysokość szczeliny obliczona ze wzoru (1) wynosi zatem ok. 0,47 $\mathrm{mm}$ i mieści się w przedziale wartości zalecanych przez producenta.

\section{Przegląd metod uszczelnienia wirników turbin gazowych}

Jednym ze sposobów zapobiegania nadmiernemu przedostawaniu się czynnika roboczego przez szczelinę między łopatkami a kadłubem jest zastosowanie wyżłobienia w końcówce łopatki (rys. 1.).

Rys. 1. Model łopatki z wyżłobieniem

Fig. 1. Model of blade with the tip chamfering

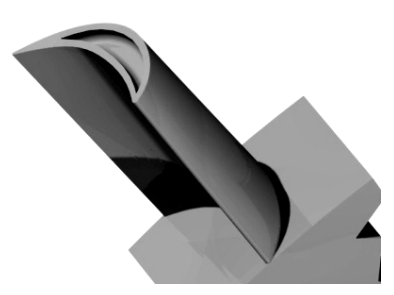

Rozwiązanie to przy odpowiednim doborze wymiarów wyżłobienia może zmniejszyć przepływ strumienia gazu z jednej strony łopatki na drugą. Badania doświadczalne wykazują, że wewnątrz wgłębienia w końcówce łopatki strumień gazu ma nieco wyższe ciśnienie niż w przypadku, gdy jest ona zakończona płasko. Również wiry powstające na skutek zakrzywienia powierzchni (rys. 2.) tworzą zauważalną barierę dla przepływającego strumienia spalin. To rozwiązanie konstrukcyjne nie pozwala jednak na znaczący wzrost sprawności turbiny. W przeprowadzonych w 1998 r. badaniach Rigby [3] stwierdził, że w zależności od głębokości wyżłobienia sprawność stopnia turbiny może wzrosnąć od 0,1 do $0,3 \%$, mimo zmniejszenia się strat przepływu czynnika roboczego w uszczelnieniu z 14 do $10 \%$. 


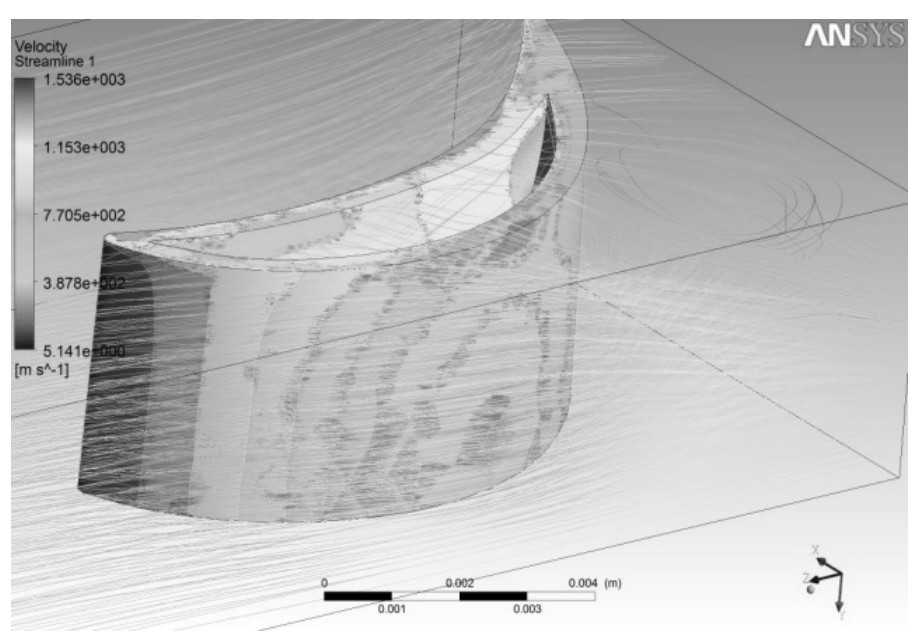

Rys. 2. Symulacja strug gazu opływających model łopatki

Fig. 2. Simulation of gas streams abounding model of the blade

Wybranie materiału tylko po jednej stronie końcówki łopatki jest kolejnym sposobem zmniejszenia strat szczelinowych (rys. 3.). Rozwiązanie to jest stosowane zarówno w turbinach gazowych, jak i w turbinach parowych. Wyżłobienie można wykonać po stronie wklęsłej albo wypukłej łopatki (rys. 4.). Tak wykonana łopatka jest jednak dużo bardziej narażona na uszkodzenia spowodowane ewentualnym wystąpieniem jej tarcia o kadłub turbiny. Przyczyną jest mniejsza wytrzymałość tej części łopatki, która tworzy jej zakończenie. Ubytek materiału powoduje, że łopatka staje się dużo bardziej podatna na zginanie, wykruszanie bądź erozję.

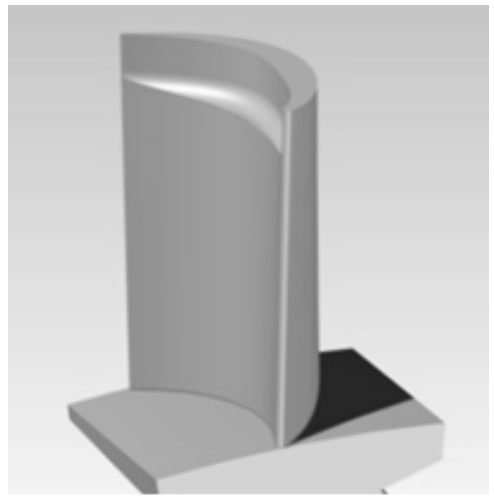

Rys. 3. Łopatka z wybraniem po jednej stronie

Fig. 3. Blade with the tip chamfering on the one side

Rozwiązanie to ma jedną zaletę - w razie awarii pierwsza zostaje uszkodzona łopatka, a dopiero później kadłub turbiny. Jest to szczególnie istotne w sytuacji, gdy kadłub turbiny nie jest specjalnie zabezpieczony przed uszko- 
dzeniami, np. przez zamontowanie płytek wykonanych z materiałów podatnych na uszkodzenia mechaniczne i jednocześnie odpornych na wysokie temperatury. Zastosowanie tych płytek powoduje, że jako pierwszy ulega uszkodzeniu korpus, a dopiero później pióro łopatki. Wybór kolejności, w jakiej mają ulegać zniszczeniu elementy konstrukcyjne, wpływa na żywotność turbiny, zmniejszenie jej wydajności, częstość napraw, a zatem i na koszty eksploatacji. Przeprowadzone przez Rigby'ego [3] badania wykazały, że największe straty szczelinowe mają łopatki, w których wybrano materiał po stronie wklęsłej, nieco niższe straty występują $\mathrm{w}$ łopatkach $\mathrm{z}$ materiałem wybranym po stronie wypukłej, a najniższe straty są w łopatkach ściętych prosto (rys. 5.). Z kolei łopatki, w których wybrano materiał po stronie wklęsłej, charakteryzują się największym przyrostem kąta odchylenia strugi, a zatem największym zmniejszeniem przyrostu składowej prędkości obwodowej.

Rys. 4. Różne rodzaje zakończeń łopatki wirnikowej: a) płasko ścięta, b) wybranie materiału po stronie wypukłej, c) wybranie materiału po stronie wklęsłej

Fig. 4. Different types of rotational blade tip: a) flat chisel, b) removing the material on the convex side, c) removing the material on the concave side
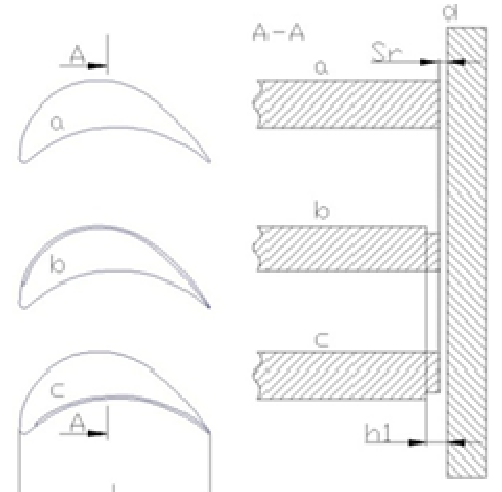

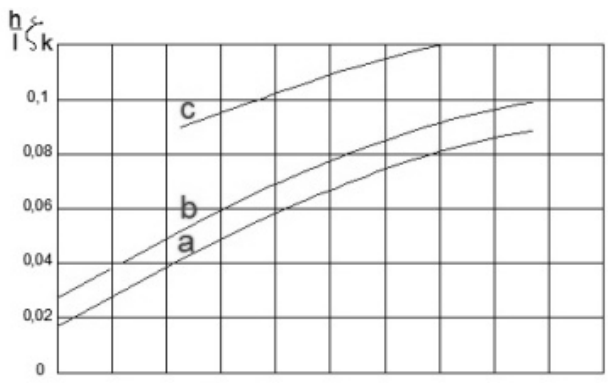
strat końcowych $\zeta_{k}$ (czyli sumy strat indukowanych $\zeta_{i}$ i szczelinowych $\left.\zeta_{s z}\right)$ oraz wartości kątów $\Delta \dot{\alpha}_{s z}$ od stosunku $S_{r} / l$ dla różnych typów końca łopatki

Fig. 5. Dependence of the final loss coefficients $\zeta_{k}$ (i.e. the sum of the losses induced $\zeta_{i}$, and slotted $\zeta_{s z}$ ) and angles values $\Delta \dot{\alpha}_{s z}$ in relation to the ratio of $S_{r} / l$ for different types of tips of the blade

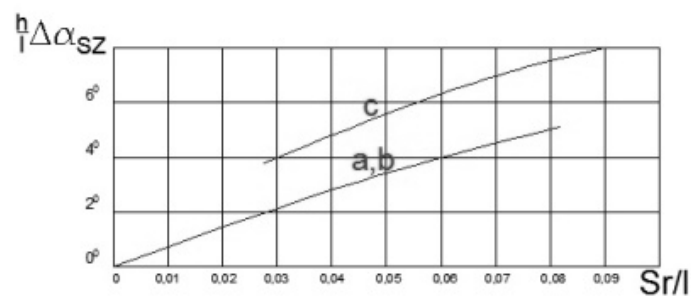


Kolejnym sposobem uszczelniania wirników turbin gazowych jest zastosowanie tzw. ,plastra miodu” (rys. 6.). Rozwiązanie to jest z powodzeniem stosowane w silnikach lotniczych oraz turbinach gazowych od ponad 20 lat. Uszczelnienie tego typu składa się $\mathrm{z}$ zamontowanych $\mathrm{w}$ kadłubie turbiny elementów $\mathrm{z}$ powłoką o strukturze plastra miodu, która nie ma bezpośredniego styku z obracającym się wirnikiem turbiny. Strukturę plastra miodu tworzą bardzo cienkie blaszki o grubości około kilkunastu mikrometrów, przylutowane bądź przyspawane do podstawy i trwale ze sobą połączone (rys. 7.). Nawet w przypadku dostania się ciał obcych do silnika czy też uszkodzenia łożysk wału głównego bądź gwałtownych manewrów samolotu, które mogą spowodować ocieranie się wirnika o korpus, „plaster miodu” nadal zachowuje swoje dobre właściwości uszczelniające. Zastosowanie tego uszczelnienia przekłada się bezpośrednio na dłuższą żywotność zespołu wirującego, większy resurs silnika, mniejszą liczbę przeglądów i napraw, a ostatecznie wpływa na zmniejszenie kosztów użytkowania silnika.
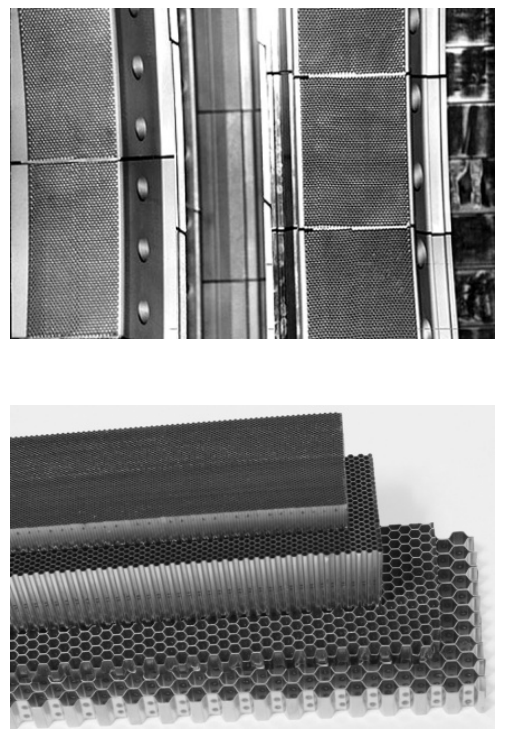

Rys. 6. Uszczelnienie typu ,plaster miodu”

Fig. 6. Honeycomb type seal

Rys. 7. Struktura uszczelnienia typu ,plaster miodu”

Fig. 7. Structure of honeycomb type seal

Do budowy plastra używa się stopów niklu o nazwie handlowej „Haynes 214” lub „Hestalloy”, charakteryzujących się dużą odpornością na utlenianie oraz zachowaniem właściwości wytrzymałościowych w temperaturach do $1200^{\circ} \mathrm{C}$. Niestety, gdy temperatura spalin w silnikach osiąga wartości ok. 1500$-1700^{\circ} \mathrm{C}$, nie można zastosować tego typu uszczelnień [6]. Z przeprowadzonych przez firmę Shanghai Turbine Corporation Limited badań [5] wynika, że sprawność turbiny z uszczelnieniem typu plaster miodu wzrasta o ok. 3,9\% w porównaniu ze stosowanymi wcześniej rozwiązaniami konstrukcyjnymi. 
Najczęściej spotykanym w praktyce sposobem uszczelniania wirników turbin jest jednak uszczelnienie labiryntowe (rys. 8.). Łopatka turbiny posiada na końcu kilka rowków, które ściśle współpracują z podobnymi rowkami wykonanymi w kadłubie (rys. 9.).

Rys. 8. Wirnik turbiny $\mathrm{z}$ elementami uszczelnienia labiryntowego

Fig. 8. Turbine rotor with the labyrinth seal elements

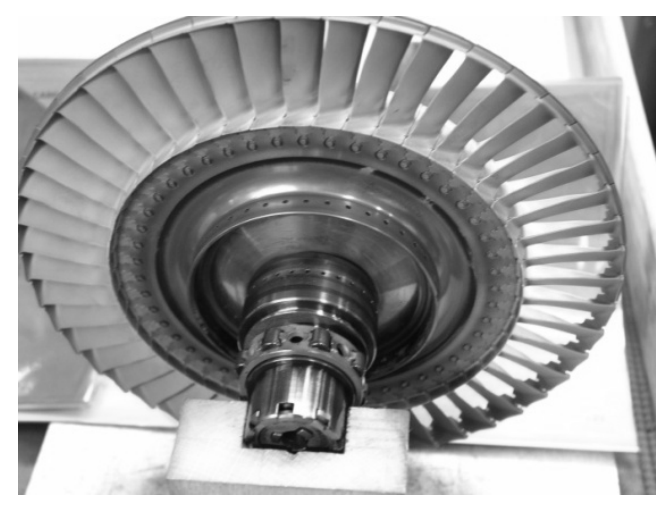

Rys. 9. Schemat uszczelnienia labiryntowego

Fig. 9. Scheme of labyrinth seal

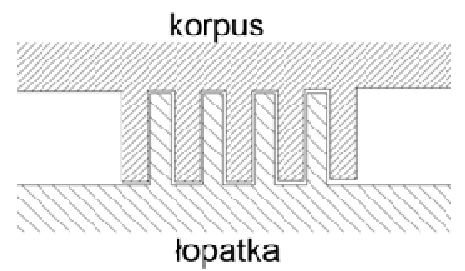

W trakcie pracy turbiny elementy labiryntów wykonanych w kadłubie i na zakończeniu łopatki nie dotykają się. Między występami i rowkami występują kolejno wąskie i szerokie szczeliny, których wymiar waha się, w zależności od rodzaju turbiny, od kilku mikrometrów do kilku milimetrów. Spaliny, płynąc przez labirynt, ulegają dławieniu izentalpowemu. W kolejnych labiryntach gaz ulega rozprężaniu politropowemu w wąskiej szczelinie, po czym wskutek procesu izobarycznej dyssypacji energii w szerszej szczelinie ulega ogrzaniu, osiągając początkową entalpię. Sprawność tego typu uszczelnienia zależy od liczby wykonanych rowków - występów. Im dłuższa jest więc droga do pokonania przez spaliny, tym mniejsze są przecieki. Dodatkowo, skomplikowany kształt kanału, przez który przepływają gazy spalinowe, powoduje bardzo silną turbulizację strugi (rys. 9.). Struga gazu porusza się ruchem chaotycznym, atomy gazu uderzają w ścianki labiryntu, częściowo zamieniając swoją energię kinetyczną w energię cieplną, która tylko w nieznacznej ilości jest odprowadzana przez łopatki i korpus, a głównie powoduje podgrzanie przepływającego czynnika. Badania tego typu uszczelnień wykazują, że sprawność silnika wzrasta przeciętnie od 2 do $7 \%$, a w niektórych przypadkach nawet do 9\% [1]. 


\section{Podsumowanie}

$\mathrm{W}$ pracy przedstawiono najczęściej stosowane w praktyce uszczelnienia pomiędzy wirnikiem a kadłubem lotniczej turbiny gazowej. Wybór odpowiedniego uszczelnienia zależy przede wszystkim od mocy silnika lotniczego. W dużych silnikach, o mocach do kilku GW, stosuje się przeważnie uszczelnienie przez wybranie materiału w łopatkach, ponieważ zjawisko pełzania materiału, z którego jest wykonana łopatka, w mniejszym stopniu może pogorszyć pracę bądź uszkodzić zespół wirnikowy. W małych silnikach, o mocy do kilkuset kW, częściej spotykanym rozwiązaniem konstrukcyjnym jest uszczelnienie labiryntowe. Zastosowanie ,plastra miodu” jako uszczelnienia jest rozwiązaniem bardzo efektywnym, ale zarazem bardzo kosztownym, o czym decydują przede wszystkim wysokie koszty jego produkcji. W porównaniu z nim zastosowanie elementów zabezpieczających kadłub jest prostsze i mniej kosztowne. Silnik jest dobrze zabezpieczony przed zniszczeniem oraz długimi okresami między kolejnymi remontami.

Wytwórcy lotniczych turbin gazowych stosują wszystkie rodzaje uszczelnień w produkowanych przez siebie silnikach. $\mathrm{O}$ wyborze uszczelnienia decydują przede wszystkim opanowanie technologii ich wytwarzania oraz własne, opatentowane rozwiązania techniczne.

\section{Literatura}

[1] Kowalski A.: Okrętowe turbozespoły spalinowe, Wydawn. Morskie, Gdynia 1983.

[2] P\&WC PW206/207 Maintenance Training Manual, Publications Customer Services, Quebec, 2012.

[3] Smarsly W. et al.: Advanced High Temperature turbine seals materials and designs, Mat. Sci. Forum, 1 (2005), www.scientific.net/MSF.492-493.21.

[4] Tuliszka E.: Turbiny cieplne: zagadnienia termodynamiczne i przepływowe, WNT, Warszawa 1973.

[5] www.forestpeholdings.com.

[6] www.ge-energy.com - Advanced Seals Upgrate.

[7] www.TurboCare.com.pl.

\section{REVIEW OF METHODS OF AVIATION TURBINE ROTORS SEALING}

\section{S u m m a r y}

In this paper, the most frequently used in practice, the prevention of leakage of exhaust gas stream between the rotor and the housing aviation gas turbine, the materials used in the construction seals and the pros and cons of each design solutions have been presented. The following 
design solutions: the seal by making a recess in the material of the rotor blade tip, a labyrinth seal for sealing, the use of wear-resistant materials (e.g. Carbide protective plate) and the materials making up the so-called „Honeycomb” have been described in detail.

Keywords: aircraft engines, gas turbines, turbine seals

DOI: $10.7862 / \mathrm{rm} .2015 .23$

Otrzymano/received: $10.01 .2015 \mathrm{r}$.

Zaakceptowano/accepted: 22.03.2015 r. 